\title{
Sources of Carbon for Hepatic Glycogen Synthesis in the Conscious Dog
}

\author{
Mary Courtney Moore, * Alan D. Cherrington,“ Gary Cline," Michael J. Pagliassotti, ${ }^{*}$ Elizabeth M. Jones, * \\ Doss W. Neal," Christine Badet," and Gerald I. Shulman" \\ *Department of Molecular Physiology and Biophysics, Vandérbilt University, Nashville, Tennessee 37232; \\ ${ }^{\ddagger}$ Department of Internal Medicine, Yale University School of Medicine, New Haven, Connecticut 06510; \\ and ${ }^{\S}$ Department of Medicine, University of Lyon, Lyon, France
}

\begin{abstract}
To identify the source(s) of carbon for the indirect pathway of hepatic glycogen synthesis, we studied nine 42-h fasted conscious dogs given a continuous intraduodenal infusion of glucose, labeled with $\left[1-{ }^{13} \mathrm{C}\right]$ glucose and $\left[3-{ }^{3} \mathrm{H}\right]$ glucose, at 8 $\mathrm{mg} \cdot \mathrm{kg}^{-1} \cdot \mathrm{min}^{-1}$ for $240 \mathrm{~min}$. Glycogen formation by the direct pathway was measured by ${ }^{13} \mathrm{C}-\mathrm{NMR}$. Net hepatic balances of glucose, gluconeogenic amino acids, lactate, and glycerol were determined using the arteriovenous difference technique. During the steady-state period (the final hour of the infusion), $81 \%$ of the glucose infused was absorbed as glucose. Net gut output of lactate and alanine accounted for $5 \%$ and $3 \%$ of the glucose infused, respectively. The cumulative net hepatic uptakes were: glucose, $15.5 \pm 3.8 \mathrm{~g}$; gluconeogenic amino acids, 32.2 \pm 2.2 mmol (2.9 $\pm 0.2 \mathrm{~g}$ of glucose equivalents); and glycerol, $6.1 \pm 0.9$ mmol (0.6 $\pm 0.1 \mathrm{~g}$ of glucose equivalents). The liver produced a net of $29.2 \pm 9.6 \mathrm{mmol}$ of lactate $(2.6 \pm 0.8 \mathrm{~g}$ of glucose equivalents). Net hepatic glycogen synthesis totaled $9.3 \pm 2.5 \mathrm{~g}$ $(1.8 \pm 0.4 \mathrm{~g} / 100 \mathrm{~g}$ liver), with the direct pathway being responsible for $57 \pm 10 \%$. Thus, net hepatic glucose uptake was sufficient to account for all glycogen formed by both the direct and indirect pathways. Total net hepatic uptake of gluconeogenic precursors (gluconeogenic amino acids, glycerol, and lactate) was able to account for only $\mathbf{2 0 \%}$ of net glycogen synthesis by the indirect pathway. In a net sense, our data are consistent with an intrahepatic origin for most of the three-carbon precursors used for indirect glycogen synthesis. (J. Clin. Invest. 1991. 88:578-587.) Key words: direct glycogen synthesis $\bullet$ glucose disposal • indirect glycogen synthesis - net hepatic balance • nuclear magnetic resonance
\end{abstract}

\section{Introduction}

It is well documented that hepatic glycogen can be formed either by a direct pathway from glucose through glucose-1phosphate and uridine diphosphate glucose or by an indirect pathway from gluconeogenic precursors (1-3). The indirect pathway apparently continues to operate even during glucose

These data were presented in part at the American Diabetes Association Annual Meeting, Atlanta, GA, June 1990.

Address reprint requests to Dr. Moore, Department of Molecular Physiology and Biophysics, 710 MRB, Vanderbilt University, Nashville, TN 37232.

Received for publication 4 October 1990 and in revised form 22 April 1991.

J. Clin. Invest.

(c) The American Society for Clinical Investigation, Inc.

$0021-9738 / 91 / 08 / 0578 / 10 \quad \$ 2.00$

Volume 88, August 1991, 578-587 infusion or carbohydrate feeding, when there is adequate glucose available to replenish glycogen via the direct pathway (4).

Lactate is thought to be a major substrate for the indirect pathway $(1,5)$, but the source(s) of lactate and other gluconeogenic precursors during glucose feeding remain(s) unclear. Although the intestine, muscle, adipose tissue, erythrocytes, and the liver itself (through cycling of glucose to three-carbon units and back into glycogen either within the individual hepatocyte or between different populations of hepatocytes) are potential sources of lactate in the postprandial period when glycogen synthesis is occurring, the significance of the contributions of these sites to indirect glycogen synthesis is unknown.

Powerful techniques are now available for the study of hepatic glycogen metabolism in vivo. The arteriovenous (A-V) difference technique, more recently making use of Doppler flow probes, allows accurate measurement of net hepatic balance of glycogenic substrates. Similarly, ${ }^{13} \mathrm{C}$-nuclear magnetic resonance (NMR) spectroscopy has proved to be a useful tool for quantitating the contribution of the direct and indirect pathways of glycogen synthesis $(5,6)$, since it allows the determination of the ${ }^{13} \mathrm{C}$ enrichment at each position of the glucosyl residues from glycogen simultaneously in the same sample. By administering $\left[1-{ }^{13} \mathrm{C}\right]$ glucose, determining the ${ }^{13} \mathrm{C}$ enrichment in portal vein glucose, and comparing it with the pattern of enrichment in hepatic glycogen, it is possible to determine the proportion of glycogen that was deposited by the direct pathway. Despite the obvious advantages of combining these techniques in a suitable animal model, there are no published reports of such a study. Therefore, we undertook a series of experiments that explored the liver's role in the disposition of an intraduodenal glucose load using the A-V difference and NMR techniques. Thus, we were able to determine the rate of glycogen synthesis, as well as the contributions of the direct and indirect pathways, and to compare these values with net hepatic balance of glucose and gluconeogenic precursors.

\section{Methods}

Animals and surgical procedures. Studies were conducted on nine 42-h fasted conscious mongrel dogs of either sex. A fast of this duration was chosen because it produces a metabolic state resembling that in the overnight-fasted human, i.e., the liver is demonstrating net uptake of lactate (7). After fasting $24 \mathrm{~h}$, the liver of the dog still exhibits net hepatic lactate output (8). Moreover, a 42-h fast reduces canine hepatic glycogen concentrations to a stable minimum (9), which was crucial for accurate determination of the glycogen synthetic rate and direct path-

1. Abbreviations used in this paper: A-P, arterial-portal; APE, atom percent excess; $\mathrm{A}-\mathrm{V}$, arteriovenous; $\mathrm{C} 1$ and $\mathrm{C} 6$, carbon atom in position 1 or 6 of glucose or glycogen; CF, correction factor; HGL, hepatic glucose load; HL, hepatic load; ICG, indocyanine green; NGB, net gut balance; NHB, net hepatic balance; NMR, nuclear magnetic resonance. 
way contribution (see Discussion). The weights of the animals ranged from 18.7 to $23.9 \mathrm{~kg}$ (mean \pm SEM $21.2 \pm 0.8 \mathrm{~kg}$ ). They were maintained on a diet of meat (Kal Kan, Vernon, CA) and chow (Purina Lab Canine Diet No. 5006, Ralston Purina Co., St. Louis, MO) composed of 34\% protein, $14.5 \%$ fat, $46 \%$ carbohydrate, and $5.5 \%$ fiber based on dry weight. The animals were housed in a facility which met American Association for Accreditation of Laboratory Animal Care (AAALAC) guidelines, and the protocol was approved by the Vanderbilt University Medical Center Animal Care Committee.

Approximately $16 \mathrm{~d}$ before study, each dog underwent a laparotomy under general anesthesia (pentobarbital sodium, $25 \mathrm{mg} / \mathrm{kg}$ ). A silicone rubber catheter was inserted into the hepatic portal vein, with the tip $2 \mathrm{~cm}$ from the point at which that vessel enters the liver. Another catheter was inserted so that its tip was $1 \mathrm{~cm}$ inside the left common hepatic vein, which carries almost half of the venous outflow of the liver, the largest volume of any of the hepatic veins (10). An additional catheter was inserted into the duodenum through a purse-string suture $3.5-4 \mathrm{~cm}$ below the pylorus. The distal tip was positioned $\sim 3 \mathrm{~cm}$ inside the bowel. Doppler flow cuffs (Instrumentation Development Laboratories, Baylor College of Medicine, Houston, TX) of 7.0 and 3.0 $\mathrm{mm}$ i.d. were positioned around the portal vein and hepatic artery, respectively (11). The proximal ends of the catheters and Doppler probe wires were brought out through the abdominal incision. The catheters were filled with heparinized saline $(200 \mathrm{U} / \mathrm{ml})$ and knotted. After closure of the muscular layer, catheters and Doppler wires were inserted into subcutaneous pockets, and the skin incision was closed. A small incision was then made in the left inguinal area, and a sampling catheter was inserted into the femoral artery and advanced into the abdominal aorta. This catheter was filled with heparinized saline, knotted, and placed in a subcutaneous pocket as described above.

$2 \mathrm{~d}$ before study, each dog had blood drawn for analysis. The dog was studied only if it had a white blood count $<18,000 / \mathrm{mm}^{3}$, a hematocrit $>38 \%$, good appetite as evidenced by consumption of all of the daily ration, and normal stools.

On the morning of the study, the proximal ends of the catheters and Doppler leads were removed from the subcutaneous pockets under local anesthesia (2\% lidocaine, Astra Pharmaceuticals, Worcester, MA). Catheter contents were aspirated and the catheters were flushed with saline. The dog was placed in a Pavlov harness, and a 20-gauge Angiocath (Deseret, Sandy, UT) was inserted in the cephalic vein.

In addition to the experimental group of 9 dogs, 11 dogs treated similarly were used to provide baseline glycogen data.

Experimental design. Each experiment began with the initiation of a constant infusion of indocyanine green (ICG) via the cephalic vein; the ICG infusion continued throughout the study and was used to confirm placement of the hepatic vein catheter and provide an independent measure of hepatic blood flow. After $80 \mathrm{~min}(-120$ to $-40 \mathrm{~min})$ of ICG equilibration, there was a $40-\mathrm{min}(-40$ to $0 \mathrm{~min})$ control period, and then a $240-\mathrm{min}(0-240 \mathrm{~min})$ study period. During the study period, a glucose infusate consisting of $20 \%$ unlabeled dextrose, $20 \%$ enriched with $\left[1-{ }^{13} \mathrm{C}\right]$ glucose, with the addition of approximately $350 \mu \mathrm{Ci}$ of $\left[3-{ }^{3} \mathrm{H}\right] \mathrm{glucose}$, was administered via the duodenostomy tube. At time 0 , a bolus of infusate sufficient to provide $0.15 \mathrm{~g}$ of unlabeled glucose/ $\mathrm{kg}(0.83 \mathrm{mmol} / \mathrm{kg})$ was given, and a constant infusion providing 8 $\mathrm{mg} \cdot \mathrm{kg}^{-1} \cdot \mathrm{min}^{-1}\left(2.66 \mathrm{mmol} \cdot \mathrm{kg}^{-1} \cdot \mathrm{h}^{-1}\right)$ was started. The infusion continued for $240 \mathrm{~min}$ to ensure that the animals reached a steady state for glucose.

Blood was drawn every 15-20 min during the control and study periods, with the total amount withdrawn not exceeding $20 \%$ of the blood volume. Each volume drawn was replaced with 2 vol of saline. The arterial and portal blood samples were collected simultaneously $\sim 30 \mathrm{~s}$ before collection of the hepatic vein sample in an attempt to compensate for transit time of glucose through the liver and thus allow accurate estimates of hepatic balance (12).

At the end of the study period, the animal was killed with an overdose of pentobarbital. The liver was rapidly removed and samples of tissue $(3 \mathrm{~g})$ from each of seven liver lobes were freeze-clamped with aluminum tongs precooled in liquid nitrogen, such that the entire pro- cess took no more than 10 min from the time of sacrifice. The position of the catheter tips was then verified to ensure proper placement.

The control dogs did not undergo experimentation but were killed after a 42-h fast, and liver samples were taken just as in the experimental animals.

Processing and analysis of samples. Immediately after each blood sample was collected, it was placed in a tube containing potassium EDTA (1.6 mg EDTA/ml; Sarstedt, Numbrecht, Federal Republic of Germany). After gentle mixing, $1 \mathrm{ml}$ of whole blood was pipetted into 3 $\mathrm{ml}$ of $4 \%$ perchloric acid. This sample was vortexed and then centrifuged at $3,200 \mathrm{rpm}$ for $10 \mathrm{~min}$. The deproteinized supernatant was frozen at $-70^{\circ} \mathrm{C}$ for later analysis of whole-blood glucose, lactate, glycerol, and alanine by the method of Lloyd et al. (13). A second aliquot $(20 \mu \mathrm{l})$ of whole blood from the arterial sample was utilized for measurement of the hematocrit in duplicate in capillary tubes. The remainder of each blood sample was centrifuged to separate the plasma and formed elements.

Six to eight $10-\mu 1$ aliquots of plasma from each sample were immediately analyzed for glucose via the glucose oxidase technique using a glucose analyzer (Beckman Instruments, Inc., Fullerton, CA). A 1-ml aliquot of plasma was added to $500 \mathrm{U}$ Trasylol (FBA Pharmaceuticals, New York) and stored at $-70^{\circ} \mathrm{C}$ for later determination of immunoreactive glucagon concentration using Unger's $30 \mathrm{~K}$ antiserum (14). A 1-ml aliquot of plasma was utilized for measurement of tritiated glucose as previously described (15). ICG concentration was measured spectrophotometrically at $805 \mathrm{~nm}$ to estimate hepatic blood flow according to the method of Leevy et al. (16). The remainder of the plasma sample was frozen at $-70^{\circ} \mathrm{C}$ for analysis of insulin and amino acids. Plasma immunoreactive insulin was measured with a Sephadex-bound antibody procedure (17). Amino acids were derivatized with phenylisothiocyanate, and concentrations were measured by reverse-phase high pressure liquid chromatography (HPLC) at $254 \mathrm{~nm}$ using a modified version of the methods of Bidlingmeyer et al. (18) and Heinrikson and Meredith (19).

The liver samples were ground to powder using mortars and pestles cooled with liquid nitrogen and were then stored at $-70^{\circ} \mathrm{C}$. The glycogen was extracted from each lobe and purified as previously described (6). The cold glycogen content of the liver was determined by the method of Keppler and Decker (20). ${ }^{13} \mathrm{C}$ enrichment patterns of the glucosyl residues within the glycogen were determined by NMR as previously described (6).

Calculations. Net hepatic balance (NHB) of glucose, lactate, glycerol, and alanine was calculated as follows:

$N H B=\left\{H-\left[\left(A \cdot Q_{\mathrm{A}}\right)+\left(P \cdot Q_{\mathrm{P}}\right)\right]\right\} \cdot H B F$,

where $A, \mathrm{P}$, and $H$ refer to the concentrations of the substrate in arterial, portal vein, and hepatic vein blood, respectively; $Q_{\mathrm{A}}$ and $Q_{\mathrm{P}}$ refer to the proportion of hepatic flow contributed by the artery and the portal vein, respectively; and $H B F$ refers to total hepatic blood flow. For NHB of amino acids, plasma concentrations and hepatic plasma flow were substituted for the corresponding blood values. Since the Doppler- and ICG-determined blood flows were very similar $(33.8 \pm 0.3$ and $34.7 \pm 0.7 \mathrm{ml} \cdot \mathrm{kg}^{-1} \cdot \mathrm{min}^{-1}$, respectively), and balance calculations performed using either yielded results which were not significantly different, the data reported here utilize only Doppler-determined blood flow. In glucose balance calculations, plasma glucose values were converted to whole-blood values by using a correction factor obtained by averaging the ratio of the whole-blood glucose value to the plasma glucose value at each time point throughout the study. A separate correction factor (CF) was established for each sampling site in each dog. Mean CFs were $0.72 \pm 0.01$ for the artery, $0.71 \pm 0.01$ (control period) and $0.68 \pm 0.01$ (infusion period) for the portal vein, and $0.70 \pm 0.02$ for the hepatic vein. For the artery and hepatic vein, one CF was used for the entire study, since the ratios between whole blood and plasma glucose were found to be the same in the control and infusion periods. Calculations performed with plasma glucose values converted to blood glucose values yield almost identical results to those performed with 
blood glucose values per se, but the variance was reduced because of the accuracy of plasma glucose A-V differences, which do not require a deproteinization step. The use of whole blood glucose ensures accurate hepatic balance measurements regardless of the characteristics of glucose entry into the erythrocyte.

The rate of substrate delivery to the liver, called the hepatic load (HL) was calculated with the formula:

$H L=\left[\left(A \cdot Q_{\mathrm{A}}\right)+\left(P \cdot Q_{\mathrm{P}}\right)\right] \cdot H B F$.

Net fractional substrate extraction by the liver was calculated as the ratio of NHB to HL. Net gut balance (NGB) was determined by multiplying the arterial-portal (A-P) substrate difference by the portal blood flow.

The percentage of glycogen synthesized by the direct pathway was determined by the following equation:

Percentage of direct pathway

$=\frac{\mathrm{C} 1 \text { glycogen }-\mathrm{C} 6 \text { glycogen }}{\mathrm{Cl}_{\mathrm{pv}} \cdot \mathrm{CF}} \cdot 100$,

where $\mathrm{C} 1$ and $\mathrm{C} 6$ glycogen represent the ${ }^{13} \mathrm{C}$ atom percent excess (APE) in positions 1 and 6 , respectively, of the glucosyl residues from hepatic glycogen, $\mathrm{Cl}_{\mathrm{pv}}$ represents the APE in carbon 1 of portal vein plasma glucose, and CF is a correction factor to account for the amount of time required for portal vein ${ }^{13} \mathrm{C}$ to reach steady state. $\mathrm{ACF}$ value was determined for each dog based on plasma samples obtained every 15-30 min throughout the glucose infusion period and analyzed by gas chromatography mass spectrometry. Thus, the expression " $\mathrm{Cl} 1_{\mathrm{pv}} \cdot \mathrm{CF}$ " represents the enrichment in the $\mathrm{Cl}$ position of the portal vein plasma glucose, corrected by the integrated area under the curve of APE plotted against time. The use of this factor assumes that hepatic glycogen synthesis proceeds in a linear fashion, as previously shown in the rat (6). The calculation was modified to compensate for the mass of the glycogen present in the liver and for the natural abundance of ${ }^{13} \mathrm{C}$ in hepatic glycogen at the beginning of the glucose infusion. Thus, the modified equation was:

Percentage of direct pathway

$=\left[\left(\frac{\left(\mathrm{C} 1 \cdot \mathrm{Gly}_{\mathrm{f}}\right)-(1.1 \cdot 2.52)}{\mathrm{Gly}_{\mathrm{f}}-2.52}\right)-\left(\frac{\left.\mathrm{C} 6 \cdot \mathrm{Gly}_{\mathrm{f}}\right)-(1.1 \cdot 2.52)}{\mathrm{Gly}_{\mathrm{f}}-2.52}\right)\right]$

$\times \frac{1}{\mathrm{C} 1_{\mathrm{pv}} \times \mathrm{CF}} \times 100$,

where $\mathrm{Gly}_{\mathrm{f}}$ is the glycogen concentration at the end of the glucose infusion ( $\mathrm{g} / 100 \mathrm{~g}$ liver), $1.1 \pm 0.5 \%$ is the natural abundance of ${ }^{13} \mathrm{C}$ in glycogen from control animals that did not receive the glucose infusion (and thus the projected natural abundance in the experimental animals at the beginning of the glucose infusion), and $2.52 \pm 0.08 \mathrm{~g} / 100 \mathrm{~g}$ liver is the glycogen concentration in the control animals (and the projected concentration in the experimental animals at the beginning of the glucose infusion). The glycogen concentrations for both the control and experimental animals are the means of the values from seven liver lobes in each dog, weighted for the proportion of the liver mass contributed by that lobe (10).

Analysis of variance (ANOVA) with a repeated measures design (or, where appropriate, a paired $t$ test) was used to evaluate changes over time within the group. Where significant changes were found, the Student-Newman-Keuls multiple range test was used for post-hoc analysis. Where appropriate, correlation coefficients were calculated, and when significant correlations were found, the method of least squares was used to obtain a linear regression equation. A $P$ value $<0.05$ was accepted as significant. Results for NMR data and net glycogen synthesis are presented as mean \pm SEM for all nine animals. Owing to the failure of sampling catheters, balance data from two animals were unavailable, and thus $n=7$ for those data.

\section{Results}

Blood glucose concentrations; hepatic glucose load, balance, and fractional extraction; and hepatic blood flow. Arterial and portal vein whole-blood glucose levels, arterial and portal vein blood flow, and the hepatic glucose load (HGL) are shown in Fig. 1. The mean arterial blood glucose level increased from $73 \pm 3 \mathrm{mg} / \mathrm{dl}$ in the control period to $125 \pm 9 \mathrm{mg} / \mathrm{dl}$ during the last hour of the infusion. The mean portal vein blood glucose concentration increased from $69 \pm 3$ to $149 \pm 9 \mathrm{mg} / \mathrm{dl}$. There were no significant changes in blood flow. The hepatic artery and the portal vein contributed $16 \%$ and $84 \%$, respectively, of the hepatic blood flow throughout the study. The HGL, a measure of the rate of glucose delivery to the liver, increased from $22.5 \pm 3.2$ to $48.0 \pm 4.8 \mathrm{mg} \cdot \mathrm{kg}^{-1} \cdot \mathrm{min}^{-1}$. Before the start of the infusion, net hepatic glucose output was $1.9 \pm 0.5 \mathrm{mg} \cdot \mathrm{kg}^{-1}$. $\min ^{-1}$ (Fig. 2). Within $15 \mathrm{~min}$ of beginning the infusion, the dogs had converted to net hepatic uptake of glucose. Net up-
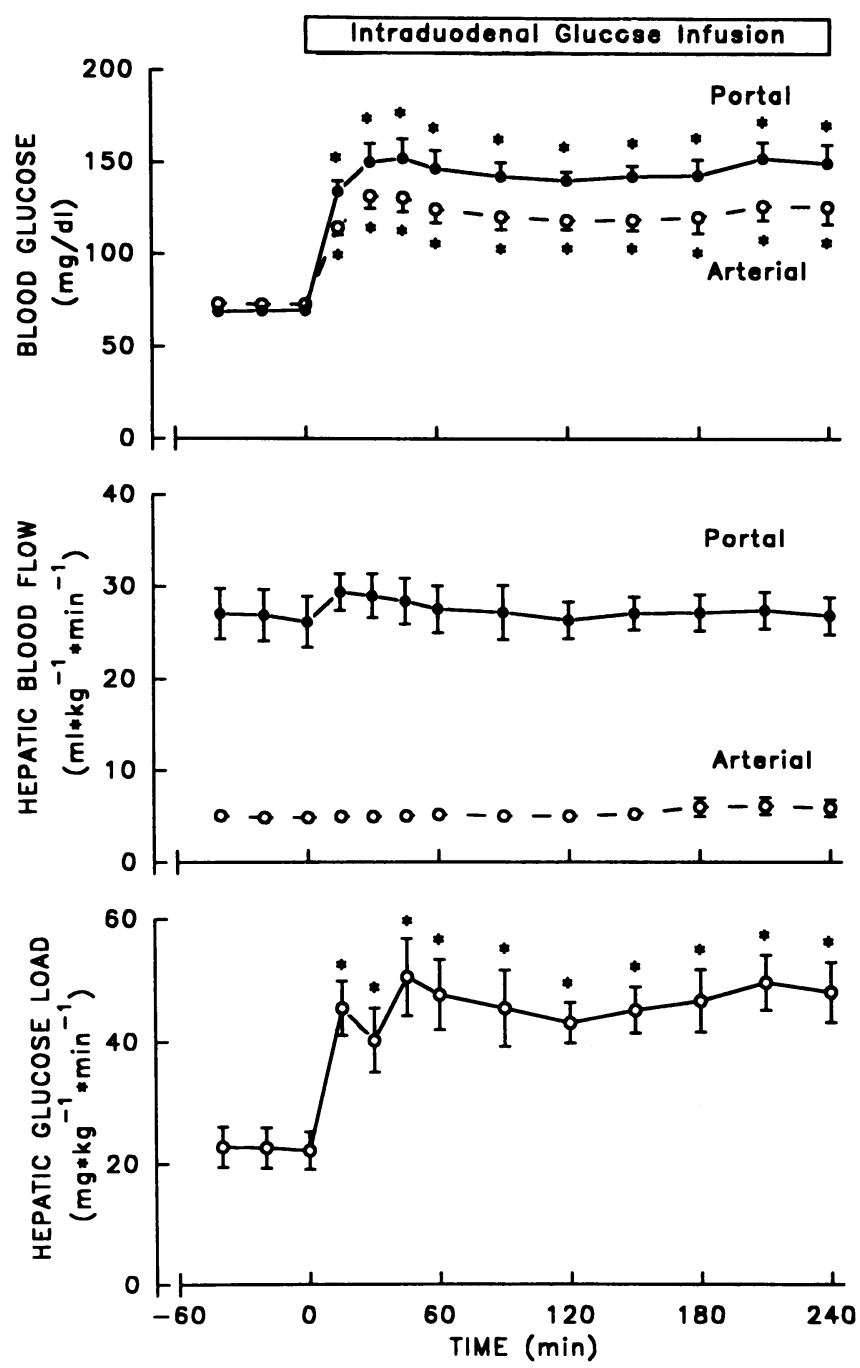

Figure 1. Arterial and portal blood glucose concentrations, hepatic artery and portal vein blood flow, and HGL during control period ( -40 to $0 \mathrm{~min}$ ) and continuous intraduodenal infusion (0-240 $\mathrm{min}$, denoted by rectangle at top of figure) of glucose at $8 \mathrm{mg} \cdot \mathrm{kg}^{-1} \cdot \mathrm{min}^{-1}$ in conscious dogs. Data represent mean \pm SEM, $n=7$. *Significantly different from control period, $P<0.05$. 

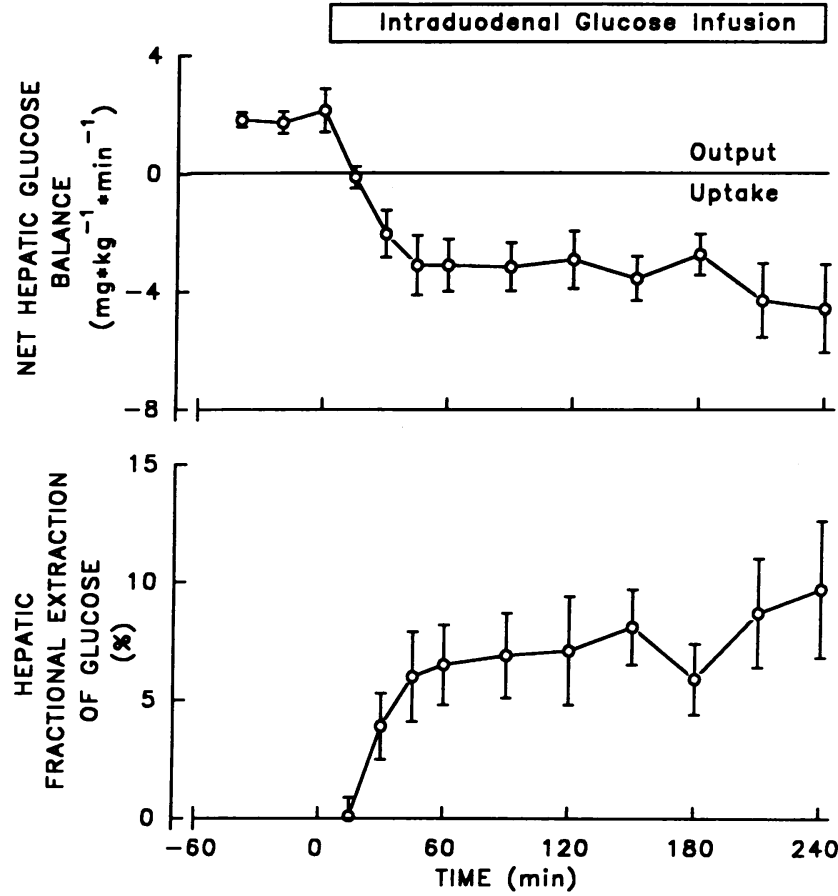

Figure 2. Net hepatic glucose balance and hepatic fractional extraction of glucose during control period ( -40 to $0 \mathrm{~min}$ ) and continuous intraduodenal infusion ( $0-240 \mathrm{~min}$, denoted by rectangle at top of figure) of glucose at $8 \mathrm{mg} \cdot \mathrm{kg}^{-1} \cdot \mathrm{min}^{-1}$ in conscious dogs. Data represent mean \pm SEM, $n=7$. Positive values indicate net hepatic output, and negative values indicate net hepatic uptake. *Significantly different from control period, $P<0.05$.

take increased gradually until it reached $4.6 \pm 1.5 \mathrm{mg} \cdot \mathrm{kg}^{-1}$. $\min ^{-1}$. Net fractional extraction of glucose reached $9.7 \pm 2.9 \%$ by the end of the study.

Gut disposition of the glucose load. The dogs received $40.7 \pm 1.6 \mathrm{~g}$ of glucose during the infusion period. Of this, $29.5 \pm 4.3 \mathrm{~g} \mathrm{(73 \% )}$ was absorbed in a net sense as glucose per se. Net lactate production by the gut totaled $10.6 \pm 2.2 \mathrm{mmol}$, or $1.0 \pm 0.2 \mathrm{~g}$ of glucose equivalents $(2.5 \%$ of the glucose administered). Net production of alanine by the gut totaled $6.8 \pm 1.1$ mmol, or $0.6 \pm 0.1 \mathrm{~g}$ of glucose equivalents $(1.5 \%$ of the glucose administered). Net gut release of glycerol was $0.4 \pm 0.2 \mathrm{mmol}$ ( $0.2 \%$ of the glucose administered). Therefore, $77 \%$ of the glucose infused could be accounted for. Most of the glucose unaccounted for was probably that remaining within the gut at the end of the study and that oxidized by the gut throughout the study. This can be seen more clearly by considering absorption only during the final hour of the experiment, when steady state conditions existed. During that time period, net glucose absorption totaled $8.3 \pm 0.8 \mathrm{~g}$ ( $81 \%$ of the glucose administered). In a net sense, the gut also produced (expressed in glucose equivalents): lactate, $0.5 \pm 0.1 \mathrm{~g}$; alanine, $0.3 \pm 0.04 \mathrm{~g}$; and glycerol, $0.04 \pm 0.02 \mathrm{~g}$ (accounting for $5 \%, 3 \%$, and $0.4 \%$, respectively, of the glucose infused). Thus, in a steady-state condition in which the glucose remaining in the gut need not be considered, almost $90 \%$ of the glucose administered could be accounted for. A substantial amount of the remainder probably underwent oxidation within the gastrointestinal tract.

Lactate concentration and metabolism. Arterial lactate levels increased by $>2.5$-fold during the glucose infusion (Fig. 3).
Mean net hepatic lactate uptake during the control period was $7.0 \pm 2.0 \mu \mathrm{mol} \cdot \mathrm{kg}^{-1} \cdot \mathrm{min}^{-1}$. Within $30 \mathrm{~min}$ after beginning the infusion, the liver changed to net hepatic output of lactate, reaching a maximum of $9.8 \pm 5.6 \mu \mathrm{mol} \cdot \mathrm{kg}^{-1} \cdot \mathrm{min}^{-1} 45 \mathrm{~min}$ after the infusion started. Net output then declined gradually, and the group exhibited net hepatic lactate uptake by the end of the infusion period.

Amino acid concentrations and metabolism. The arterial blood alanine concentration, net hepatic alanine uptake, and hepatic fractional extraction of alanine did not change significantly during the study (data not shown). Also, when the values for the gluconeogenic amino acids (serine, threonine, glycine, alanine, glutamate, and glutamine) were totaled, their arterial concentration, net hepatic uptake, and fractional extraction did not differ during the control period and the glucose infusion period (data not shown).

Glycerol concentration and metabolism. The arterial glycerol concentration declined by more than half during the glucose infusion period (Fig. 4). Net hepatic glycerol uptake decreased from $2.2 \pm 0.3 \mu \mathrm{mol} \cdot \mathrm{kg}^{-1} \cdot \mathrm{min}^{-1}$ in the control period to $1.0 \pm 0.3 \mu \mathrm{mol} \cdot \mathrm{kg}^{-1} \cdot \mathrm{min}^{-1}$ during the final hour of the study $(P<0.05)$.

Hormonal concentrations. Mean control period arterial insulin levels were $9 \pm 2 \mu \mathrm{U} / \mathrm{ml}$. Levels peaked at $60 \pm 16 \mu \mathrm{U} / \mathrm{ml}$, then plateaued at $48 \pm 14$ (Fig. 5). Control period glucagon levels were $69 \pm 9 \mathrm{pg} / \mathrm{ml}$. Glucagon levels declined during the glucose infusion period, reaching $37 \pm 3 \mathrm{pg} / \mathrm{ml}$ by the final time point of the study.
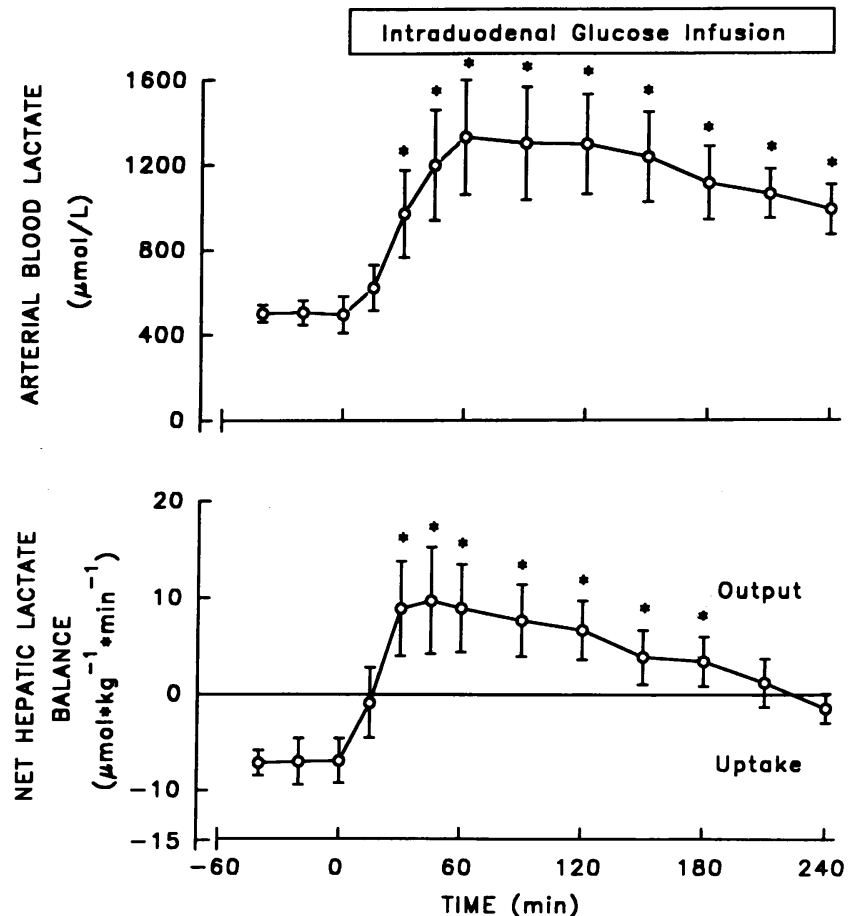

Figure 3. Arterial blood lactate levels and net hepatic lactate balance during control period ( -40 to $0 \mathrm{~min}$ ) and continuous intraduodenal infusion (0-240 min, denoted by rectangle at top of figure) of glucose at $8 \mathrm{mg} \cdot \mathrm{kg}^{-1} \cdot \mathrm{min}^{-1}$ in conscious dogs. Data represent mean $\pm \mathrm{SEM}$, $n=7$. For balance data, positive values indicate net hepatic output, and negative values indicate net hepatic uptake. *Significantly different from control period, $P<0.05$. 


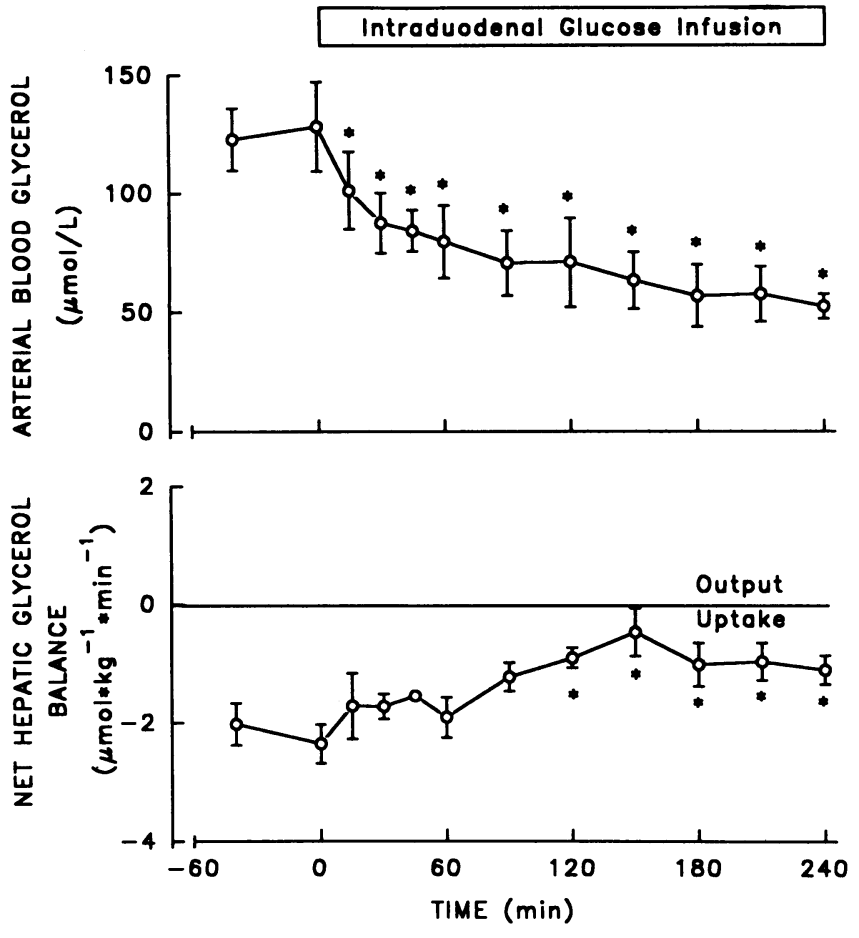

Figure 4. Arterial blood glycerol levels and net hepatic glycerol uptake during control period ( -40 to $0 \mathrm{~min}$ ) and continuous intraduodenal infusion (0-240 min, denoted by rectangle at top of figure) of glucose at $8 \mathrm{mg} \cdot \mathrm{kg}^{-1} \cdot \mathrm{min}^{-1}$ in conscious dogs. Data represent mean $\pm \mathrm{SEM}$, $n=7$. For balance data, positive values indicate net hepatic output, and negative values indicate net hepatic uptake. *Significantly different from control period, $P<0.05$.

Hepatic disposition of glucose and gluconeogenic precursors; pathways of glycogen synthesis. The cumulative net glucose uptake by the liver was $15.5 \pm 3.8 \mathrm{~g}$ (Fig. 6). In a net sense, the liver also took up $32.2 \pm 2.2 \mathrm{mmol}$ gluconeogenic amino acids ( $2.9 \mathrm{~g}$ of glucose equivalents) and $6.1 \pm 0.9 \mathrm{mmol}$ glycerol ( $0.6 \mathrm{~g}$ of glucose equivalents). Net hepatic lactate output was $29.2 \pm 9.6 \mathrm{mmol}$, or $2.6 \mathrm{~g}$ of glucose equivalents. The final hepatic glycogen concentrations for the experimental dogs are listed in Table $\mathrm{I}$. Net hepatic glycogen synthesis totaled 9.3 \pm 2.5 $\mathrm{g}$ (range, 3.4-20.3 g). NMR analysis revealed that $57 \pm 10 \%$ of the glycogen was formed via the direct pathway (Table II).

Correlational analyses. There was a significant inverse correlation $(r=-0.68, P<0.05 ; y=-15.07 x+77.44)$ between the mass of hepatic glycogen synthesized (expressed in grams per 100 grams of liver) and the proportion of glycogen deposited by the direct pathway. However, there was no significant correlation between net hepatic glucose uptake and the amount of glycogen synthesized, net hepatic glucose uptake and proportion of glycogen synthesized by the direct pathway, net hepatic gluconeogenic precursor (gluconeogenic amino acids and glycerol) uptake and pathway of glycogen synthesis, or net hepatic balance of all gluconeogenic precursors (gluconeogenic amino acids, glycerol, and lactate) and pathway of glycogen synthesis. Neither were there any significant correlations between insulin and glucagon (levels during the control and infusion periods, changes in levels of either hormone, peak or lowest levels, or changes in their molar ratios) and net hepatic glucose balance, mass of glycogen synthesized, or pathway of glycogen synthesis.

\section{Discussion}

Several previous investigations have examined the disposition of a glucose meal (21-23), but the current data are unique in that they were obtained during a continuous glucose infusion, permitting A-V difference observations during a steady-state period of absorption in the conscious dog, and they incorporated NMR methodology.

Over the 4-h infusion period, only $73 \%$ of the glucose administered was absorbed as glucose. This increases to $81 \%$ if only the last hour of the study is considered. By examining the steady-state period during the last hour of the study when the gut was already filled with glucose, we obviated the necessity of considering unabsorbed glucose. Absorption of glucose and gut production of lactate and amino acids during the final hour in the current study were very similar to the results obtained by Abumrad et al. (21) using combined A-V difference and tracer techniques in dogs given a bolus intragastric glucose load. Although we did not measure $\mathrm{CO}_{2}$ production, presumably it would not be less than the amount found in the study by Abumrad et al. (21), where it accounted for $4 \%$ of the glucose load. Therefore it probably accounted for a major portion of the glucose remaining unaccounted for.

In the present study, the net glucose uptake by the liver $(15.5 \mathrm{~g})$ was the equivalent of $53 \%$ of the net glucose which was absorbed (38\% of the glucose administered). Hepatic balance measurements would tend to underestimate glucose uptake by the liver if hepatic production of glucose continued during the glucose infusion. However, the ratio of the specific activity of tritiated glucose in the hepatic vein to the combined hepatic
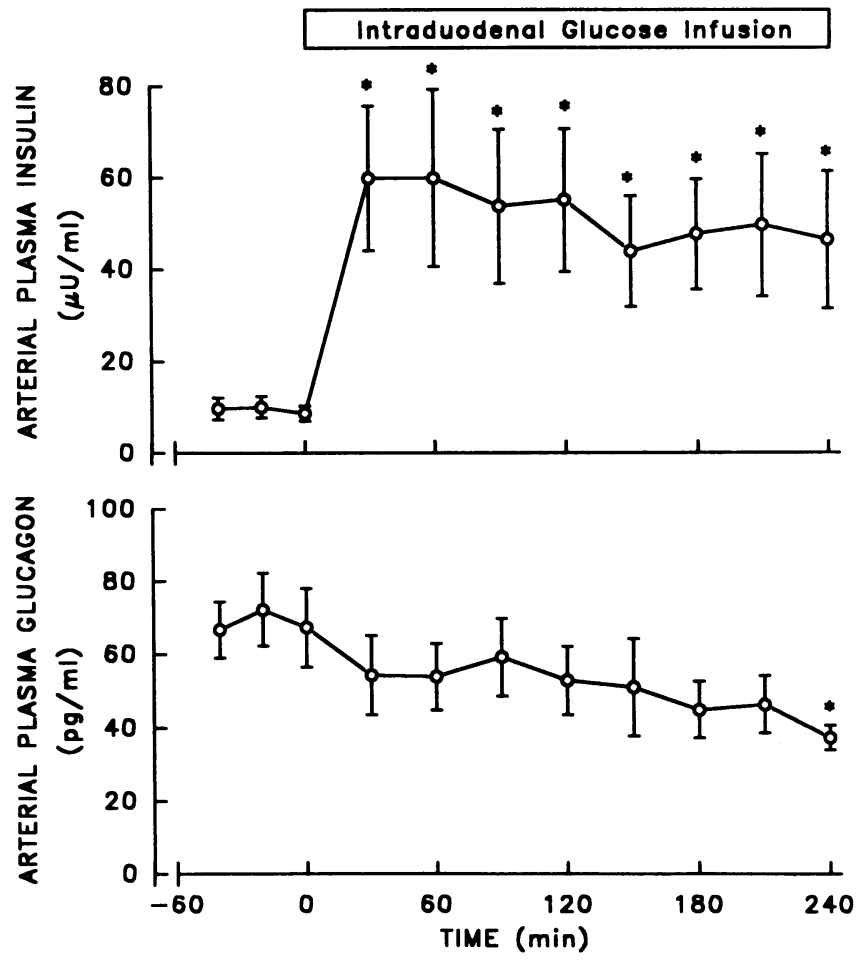

Figure 5. Arterial plasma insulin and glucagon concentrations during control period ( -40 to $0 \mathrm{~min}$ ) and continuous intraduodenal infusion (0-240 min, denoted by rectangle at top of figure) of glucose at 8 $\mathrm{mg} \cdot \mathrm{kg}^{-1} \cdot \mathrm{min}^{-1}$ in conscious dogs. Data represent mean $\pm \mathrm{SEM}, n$ $=7$. *Significantly different from control period, $P<0.05$. 


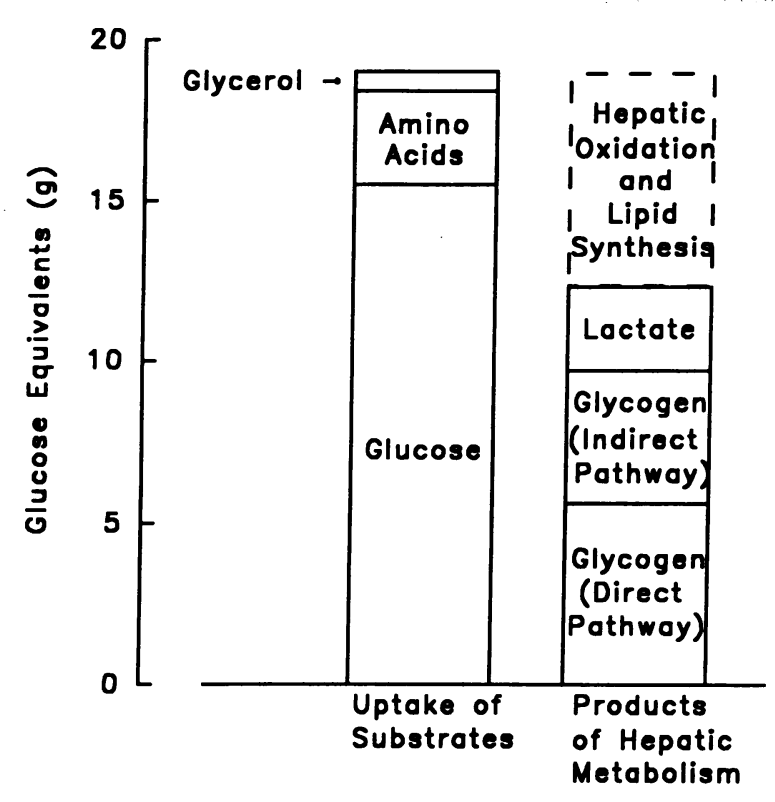

Figure 6. Cumulative hepatic balance during intraduodenal glucose infusion in conscious dogs. The bar on the left shows net hepatic uptake of glucose, gluconeogenic amino acids, and glycerol. The bar on the right shows the products of hepatic metabolism (glycogen synthesized and lactate released), with the dotted area representing carbon available for hepatic oxidation and lipogenesis; $n=7$.

artery and portal vein specific activities (weighted according to the proportion of hepatic blood flow provided by each vessel) remained constant at $1.00 \pm 0.02$ throughout the infusion period. Since there was no dilution of the specific activity of glucose across the liver, hepatic glucose production must have been essentially nil and thus the balance measurements accurately reflect hepatic uptake of glucose.

Approximately $1 \mathrm{~g} \mathrm{(3 \% )}$ of the absorbed glucose remained within the glucose space, leaving $44 \%$ of the net absorbed glucose, or $13 \mathrm{~g}$, to be disposed of by nonhepatic tissues. If the assumption is made that non-insulin-dependent tissues (i.e., the central nervous system and formed elements of the blood) took up $75 \%$ of the glucose produced by the liver during the control period $(24,25)$ and that the amount taken up by these tissues did not change during glucose infusion, then they disposed of $\sim 7 \mathrm{~g}$ of glucose (24\% of the absorbed glucose) during the glucose infusion period, leaving $\sim 6 \mathrm{~g}$ (20\% of that absorbed) for uptake by muscle and adipose tissue. Thus, the liver disposed of more than twice as much glucose as muscle and adipose tissue. These data lead to a different conclusion than do some previously published reports $(21,26,27)$, which indicate that the liver disposes of only $21-24 \%$ of an oral glucose load. However, when the data from the published reports (21, $26,27)$ are expressed in terms of the proportion of glucose absorbed, rather than that administered, it is clear that the liver is actually responsible for disposal of $\sim 30-35 \%$ of the glucose. The substantial fall in glucagon levels during the glucose infusion no doubt enhanced the importance of the liver in glucose disposal in our animals; glucagon levels did not change (21) or were not reported by other investigators $(26,27)$. The remainder of the difference between our findings and those of others can be explained by differences in study design. First, our techniques made possible more accurate measurements of net gut and hepatic balance. We provided the animals with a constant infusion of glucose, achieving a steady state, while the other investigators $(21,26,27)$ administered bolus loads. We also utilized Doppler-determined blood flow, whereas others used dye-extraction methodology. In this way, we had an accurate measurement of the distribution of blood flow between the hepatic artery and portal vein, which further improved our ability to calculate balance. Second, our infusion resulted in creation of a negative arterial-portal, or A-P, glucose gradient (portal glucose level greater than arterial) and in doubling of the hepatic glucose load for $4 \mathrm{~h}$. As we have previously reported, the negative A-P gradient appears to be particularly

Table I. Hepatic Glycogen Concentration at the End of the Glucose Infusion Period

\begin{tabular}{|c|c|c|c|c|c|c|c|c|c|}
\hline \multirow[b]{2}{*}{ Dog no. } & \multicolumn{7}{|c|}{ Lobe } & \multirow[b]{2}{*}{$\begin{array}{l}\text { Unweighted } \\
\text { mean }\end{array}$} & \multirow[b]{2}{*}{$\begin{array}{c}\text { Weighted } \\
\text { mean* }\end{array}$} \\
\hline & Caudate & $\begin{array}{l}\text { Left } \\
\text { central }\end{array}$ & $\begin{array}{c}\text { Left } \\
\text { lateral }\end{array}$ & $\begin{array}{c}\text { Left } \\
\text { posterior }\end{array}$ & Quadrate & $\begin{array}{l}\text { Right } \\
\text { lateral }\end{array}$ & $\begin{array}{l}\text { Right } \\
\text { central }\end{array}$ & & \\
\hline & \multicolumn{9}{|c|}{ g/loo g tissue } \\
\hline 1 & 6.28 & 6.72 & 6.10 & 5.93 & 5.86 & 5.46 & 5.13 & 5.93 & 5.80 \\
\hline 2 & 5.30 & 5.99 & 5.24 & 5.51 & 5.87 & 5.79 & 4.90 & 5.51 & 5.42 \\
\hline 3 & 4.49 & 5.37 & 4.92 & 5.61 & 3.57 & 6.07 & 4.43 & 4.92 & 4.96 \\
\hline 4 & 4.76 & 4.51 & 4.56 & 3.70 & 3.67 & 3.67 & 3.52 & 4.06 & 4.03 \\
\hline 5 & 3.93 & 4.73 & 2.64 & 2.85 & 3.89 & 3.99 & 3.00 & 3.57 & 3.45 \\
\hline 6 & 3.65 & 2.88 & 2.68 & 4.01 & 3.06 & 3.60 & 3.50 & 3.34 & 3.18 \\
\hline 7 & 3.50 & 2.88 & 2.70 & 3.72 & 3.11 & 3.53 & 3.73 & 3.31 & 3.19 \\
\hline 8 & 5.72 & 5.40 & 6.24 & 5.59 & 5.50 & 5.47 & 5.21 & 5.59 & 5.59 \\
\hline 9 & 5.48 & 6.22 & 2.92 & 5.47 & 5.32 & 4.81 & 5.25 & 5.07 & 4.66 \\
\hline Mean & 4.79 & 4.97 & 4.22 & 4.71 & 4.43 & 4.71 & 4.30 & 4.59 & 4.48 \\
\hline \pm SEM & 0.34 & 0.48 & 0.53 & 0.40 & 0.42 & 0.36 & 0.31 & 0.36 & 0.37 \\
\hline
\end{tabular}

* Weighted for the proportion of the liver mass contributed by each lobe (caudate, 7\%; left central, 13\%; left lateral, 26\%; left posterior, $5 \%$; quadrate, $10 \%$; right lateral, $21 \%$; right central, $17 \%$; reference 10 ). 
Table II. Comparison of Net Hepatic Balance of Gluconeogenic Substrates with Net Hepatic Glycogen Synthesis and NMR-determined Contribution of the Direct Pathway during the Glucose Infusion Period

\begin{tabular}{|c|c|c|c|c|c|c|c|c|}
\hline \multirow[b]{3}{*}{ Dog no. } & \multicolumn{2}{|c|}{ NHB of gluconeogenic substrates } & \multicolumn{4}{|c|}{${ }^{13} \mathrm{C}-\mathrm{NMR}$ and GC-MS data } & \multirow{3}{*}{$\begin{array}{c}\text { Direct } \\
\text { pathway }\end{array}$} & \multirow{3}{*}{$\begin{array}{c}\text { Net } \\
\text { glycogen } \\
\text { synthesis }\end{array}$} \\
\hline & \multirow[b]{2}{*}{$\begin{array}{l}\text { Uptake of } \\
\text { carbon* }\end{array}$} & \multirow[b]{2}{*}{$\begin{array}{l}\text { Output of } \\
\text { lactate }\end{array}$} & \multicolumn{2}{|c|}{${ }^{13} \mathrm{C}$ Enrichment in glycogen } & \multirow{2}{*}{$\begin{array}{l}{ }^{13} \mathrm{C} \text { APE } \\
\text { in } C_{1} \text { of } \\
\text { PV glucose }\end{array}$} & \multirow[b]{2}{*}{$\mathrm{CF}$} & & \\
\hline & & & $\mathrm{C}_{1}$ & $\mathrm{C}_{6}$ & & & & \\
\hline & $g$ of glucose & valents $/ 100 \mathrm{~g}$ & & & & & $\%$ & g/lo0 g liver \\
\hline 1 & 0.49 & 0.72 & $4.5 \pm 0.4$ & $1.1 \pm 0.1$ & 20.2 & 0.86 & 34 & 3.28 \\
\hline 2 & 0.80 & 0.01 & $3.3 \pm 0.2$ & $1.2 \pm 0.02$ & 19.8 & 0.89 & 22 & 2.90 \\
\hline 3 & 0.68 & 0.58 & $7.5 \pm 0.02$ & $1.2 \pm 0.07$ & 20.0 & 0.86 & 74 & 2.44 \\
\hline 4 & 0.82 & 1.35 & $4.0 \pm 0.2$ & $1.2 \pm 0.1$ & 19.6 & 0.85 & 45 & 1.51 \\
\hline 5 & 0.49 & 0.63 & $5.6 \pm 0.8$ & $1.4 \pm 0.1$ & 18.6 & 0.92 & 91 & 0.93 \\
\hline 6 & 0.69 & 0.15 & $3.3 \pm 0.2$ & $1.1 \pm 0.06$ & 20.3 & 0.86 & 61 & 0.66 \\
\hline 7 & 0.62 & 0.14 & $3.9 \pm 0.4$ & $1.2 \pm 0.07$ & 19.3 & 0.90 & 72 & 0.67 \\
\hline (8) & & & $-3.0 \pm 0.2$ & $1.3 \pm 0.9$ & 18.6 & 0.80 & 21 & 3.07 \\
\hline (9) & & & $3.4 \pm 0.3$ & $1.4 \pm 0.08$ & 21.1 & 0.87 & 24 & 2.14 \\
\hline $\begin{array}{c}\text { Mean } \pm \text { SEM } \\
(\text { Mean } \pm \text { SEM })^{\ddagger}\end{array}$ & $0.66 \pm 0.27$ & $0.51 \pm 0.19$ & $\begin{array}{c}4.6 \pm 0.3 \\
(4.3 \pm 0.5)\end{array}$ & $\begin{array}{c}1.2 \pm 0.1 \\
(1.2 \pm 0.04)\end{array}$ & $\begin{array}{c}19.8 \pm 0.2 \\
(19.7 \pm 0.03)\end{array}$ & $\begin{array}{c}0.88 \pm 0.01 \\
(0.87 \pm 0.01)\end{array}$ & $\begin{array}{l}57 \pm 10 \\
(49 \pm 9)\end{array}$ & $\begin{array}{c}1.77 \pm 0.45 \\
(1.96 \pm 0.37)\end{array}$ \\
\hline
\end{tabular}

* Gluconeogenic amino acids and glycerol. ${ }^{*}$ Values not in parentheses are those for the seven dogs for which all data are available; values in parentheses include those seven dogs, as well as the two for which balance data are not available. Abbreviations: $C_{1}$ and $C_{6}$, carbons 1 and 6; GC-MS, gas chromatography mass spectrometry; PV, portal vein.

important in producing a signal which stimulates net hepatic glucose uptake (28). Up to a gradient of $\sim-14 \mathrm{mg} / \mathrm{dl}$, net hepatic glucose uptake is dependent on the magnitude of the negative A-P gradient, with the effect appearing to saturate at larger gradients (Pagliassotti et al., manuscript submitted for publication). In our study, an A-P gradient of $-14 \mathrm{mg} / \mathrm{dl}$ or greater was maintained for the entire 4-h period of glucose infusion. In studies employing bolus enteral glucose administration, a gradient of $-14 \mathrm{mg} / \mathrm{dl}$ or more existed for only about $2 \mathrm{~h}$ $(21,26,27)$. The present data are consistent with those obtained during continuous intraportal glucose infusion. With insulin fixed at a level approximately fourfold basal, the infusion of glucose intraportally so that the hepatic glucose load doubled was associated with net hepatic uptake of $38-52 \%$ of the infused glucose (28; Pagliassotti et al., manuscript submitted for publication). Therefore, it appears that the liver disposes of one-third to one-half of the glucose absorbed from an enteral load, the exact amount depending on the manner (bolus or constant infusion) in which the glucose is delivered.

The mean contribution of the direct pathway as determined by NMR ( $57 \%$ for the seven dogs with all balance data available [Table II]), is similar to the $50 \%$ contribution by the direct pathway found during intravenous glucose infusions in overnight-fasted human volunteers (4). When the data from all nine dogs is considered, the contribution of the direct pathway, $49 \%$, is even closer to the value obtained in humans (4). The glycogen concentration following the glucose infusion and the total mass of glycogen synthesized by the different dogs varied widely (Tables I and II), as did the percentage contribution of the direct pathway and the net hepatic glucose uptake. In this regard, it is interesting to note that the hepatic glycogen concentration in the animals varied both from lobe to lobe in the same liver and from animal to animal (Table I). Thus, glycogen concentrations derived from samples taken at only one or two sites within the liver might not have been representative of the entire liver.

Some of the variability apparent in the experimental animals may be a result of the fact that calculation of both the glycogen synthetic rate and the direct pathway contribution relied upon a comparison of the final hepatic glycogen concentration in the experimental animals with the glycogen concentration in 42-h fasted dogs which did not receive the glucose infusion. It is possible that some of the experimental animals had baseline glycogen concentrations which differed from the mean of the control animals. However, a large control group (11 animals) was used in order to minimize the likelihood of error, and studies were conducted on animals fasted long enough so that hepatic glycogen levels had reached stable levels (9). The mean concentrations in the individual control dogs were remarkably similar: $2.73,2.78,2.45,2.64,2.79,2.67$, $2.62,2.07,2.02,2.48$, and $2.49 \mathrm{~g} / 100 \mathrm{~g}$ liver. Thus our data indicate that the variability in glycogen synthetic rate and contribution of the direct pathway is a result of differences in response of the individual dogs to the glucose infusion and not variability in their baseline glycogen concentrations. Moreover, the glycogen synthetic rate apparent in the current study, $1.8 \pm 0.5 \mathrm{mg} \cdot \mathrm{kg}^{-1} \cdot \mathrm{min}^{-1}$, was similar to that previously reported during glucose administration in humans (29) and dogs (30). It is noteworthy that marked variability in response to administration of a glucose load has previously been observed in both dogs $(21,26)$ and humans $(31,32)$. In the present study, the mass of glycogen synthesized by the direct pathway fell within a relatively narrow range $(0.4-1.1 \mathrm{~g} / 100 \mathrm{~g}$ liver), except in one animal $(\operatorname{dog} 3,1.8 \mathrm{~g} / 100 \mathrm{~g}$ liver), whereas the amount synthesized by the indirect pathway was extremely variable $(0.1-2.4 \mathrm{~g} / 100 \mathrm{~g}$ liver). Animals with the greatest net glycogen synthesis exhibited the smallest percentage contribution by the direct pathway. The factor(s) determining the rate of indirect 
synthesis are not clear. Although there were no correlations between hormonal levels and changes and the pathways of glycogen synthesis, it is notable that $\operatorname{dog} 3$, which had an unusually large mass of glycogen deposited via the direct pathway, experienced an increase in plasma insulin concentration (to a level that was fourfold the mean of the other dogs) during the final hour of the glucose infusion.

The current data are consistent with the hypothesis (33) that the three-carbon substrates used for glycogen synthesis by the indirect pathway are intrahepatic in origin. Approximately $1.0 \mathrm{mg} \cdot \mathrm{kg}^{-1} \cdot \mathrm{min}^{-1}$ of glycogen was deposited by the direct route and $0.8 \mathrm{mg} \cdot \mathrm{kg}^{-1} \cdot \mathrm{min}^{-1}$ by the indirect route. Net uptake of gluconeogenic precursors (gluconeogenic amino acids, glycerol, and lactate) was sufficient to account for only $20 \%$ of net glycogen synthesis via the indirect pathway (Table II), whereas net hepatic glucose uptake $\left(3.0 \pm 0.7 \mathrm{mg} \cdot \mathrm{kg}^{-1} \cdot \mathrm{min}^{-1}\right)$ was adequate to account for all glycogen synthesis, with additional available for hepatic oxidation and lipogenesis. Although hepatic oxidation was not measured, it can be estimated to be $\sim 3 \mathrm{~g}$ of glucose, or $0.6 \mathrm{mg} \cdot \mathrm{kg}^{-1} \cdot \min ^{-1}(34,35)$. In vitro studies have shown hepatic lipogenic rates to be low, accounting for only $\sim 5 \%$ of hepatic glucose uptake (34), which would be equal to $0.15 \mathrm{mg} \cdot \mathrm{kg}^{-1} \cdot \mathrm{min}^{-1}$ in this study, but little is known about the rate of lipogenesis in vivo under conditions such as we employed. Net hepatic uptake of gluconeogenic amino acids $(0.6 \mathrm{mg}$ of glucose equivalents $\left.\cdot \mathrm{kg}^{-1} \cdot \mathrm{min}^{-1}\right)$ and net output of lactate $(0.5 \mathrm{mg}$ of glucose equivalents $\cdot \mathrm{kg}^{-1} \cdot \mathrm{min}^{-1}$ ) were remarkably similar. In this regard, it is important to note that we relied upon plasma, rather than whole blood, amino acid concentrations. However, net hepatic balance is either no different, or net hepatic uptake is even greater, when plasma gluconeogenic amino acid values are used rather than whole-blood values $(36,37)$. Our calculated net hepatic uptake of total gluconeogenic amino acids is thus the same as or greater than the value we would have obtained using whole-blood concentrations. The net hepatic uptake of glycerol and the net hepatic output of pyruvate (estimated at $\sim 10 \%$ of that of lactate) were trivial. Thus, the NHB of the total of all gluconeogenic precursors was approximately zero.

There are at least two possible sources of three-carbon substrates (primarily lactate) for indirect glycogen synthesis which would be consistent with our findings. The first is that intrahepatic glycolysis is responsible for the production of virtually all of the lactate utilized (i.e., the NHB measurements are an accurate reflection of the total hepatic uptake of precusors). Cycling of glucose to three-carbon units and back into glycogen could occur either within the individual hepatocyte or between different populations of hepatocytes. In regard to the latter possibility, the hepatic parenchyma displays a remarkable degree of zonal heterogeneity which has given rise to the concept of "metabolic zonation" (38). The perivenous cells have high glucokinase and pyruvate kinase activities, giving them the greater capacity for glycolysis and for synthesis of glycogen by the direct pathway. In contrast, the periportal cells are richer in phosphoenolpyruvate carboxykinase, fructose 1,6-bisphosphatase, glucose 6-phosphatase, lactate dehydrogenase, and aminotransferase activity, and thus are better suited for gluconeogenesis and synthesis of glycogen by the indirect pathway. Thus, intrahepatic glycolysis is theoretically a feasible source of three-carbon substrates for glycogen synthesis.
A second possibility is that lactate carbon was derived from nonhepatic tissues. This implies that there was uptake of lactate by the liver, even though there was net lactate output, suggesting that the total hepatic lactate production was greater than the net production. Net balance measurements underestimate absolute uptake or production of substrates which are both taken up and released by an organ, since they reflect the quantitatively dominant process. Thus, we cannot rule out this explanation of our findings. The lactate being taken up by the liver could come from two sources. First, lactate released by the liver could be taken up by nonhepatic tissues, then re-released and taken up by the liver. If this were the case, the liver would still be responsible for producing the lactate used for indirect glycogenesis. Second, the lactate taken up by the liver could be derived from glucose metabolized by nonhepatic tissues. Muscle glycogen synthesis would have been very active under the hyperglycemic, hyperinsulinemic conditions existing during the glucose infusion period, accounting for the disposition of almost all of the $6 \mathrm{~g}$ of glucose available to the muscle and adipose tissue $(39,40)$. Adipose tissue produces lactate after glucose ingestion, although the amount released is controversial $(41,42)$. The net adipose tissue lactate output in our animals could be estimated to be $0.2-0.5 \mathrm{~g}$ of glucose equivalents $(42,43)$, an amount which would have made a trivial contribution to total hepatic glycogen synthesis. Neither skin nor noninsulin-dependent tissues such as the brain are likely sources of a significant amount of lactate, since their basal output is low and they do not increase their net lactate production following a glucose load $(44,45)$. The gut was the primary nonhepatic organ exhibiting net lactate release in our animals. However, the gut in our dogs did not increase its net output of lactate significantly in response to enteral glucose administration $\left(1.9 \pm 0.5 \mu \mathrm{mol} \cdot \mathrm{kg}^{-1} \cdot \mathrm{min}^{-1}\right.$ during the control period vs. $2.1 \pm 0.7 \mu \mathrm{mol} \cdot \mathrm{kg}^{-1} \cdot \mathrm{min}^{-1}$ during the glucose infusion), in accord with previously reported data (27). The cumulative net output of lactate by the gut during the glucose infusion period was $1.0 \pm 0.2 \mathrm{~g}$ of glucose equivalents. Although it is possible that our methods underestimated the absolute production of lactate by the gut, they present an accurate picture of the net release of lactate. It is clear that lactate from a variety of tissues mixes in the vascular pool. Although some of the carbon being deposited in hepatic glycogen via the indirect pathway undoubtedly comes from these sources, the liver must have been the source of the three-carbon precursors for the indirect pathway in a net sense, since the net hepatic balance of gluconeogenic substrates was approximately zero.

While this paper was under review, a report was published by Mitrakou et al. (46) describing the results of a study examining the disposition of an oral glucose load in conscious dogs, using net balance as well as isotopic methods. The data of Mitrakou et al. (46) are remarkably consistent with ours. Glycogen synthetic rates were very similar in both groups of dogs, and these investigators noted, as did we, that net hepatic glucose uptake was sufficient to allow for all hepatic glycogen synthesis. Despite the difference in the period of fasting before study ( $18 \mathrm{~h}$ for the animals in Mitrakou et al. vs. $42 \mathrm{~h}$ in ours), the contribution of the direct pathway was almost the same ( $52 \%$ vs. $57 \%$, respectively). The primary difference was that there was sufficient uptake of three-carbon substrates in the dogs studied by Mitrakou et al. to account for the glycogen synthesized via the indirect pathway, while this was not the 
case in our animals. Nevertheless, these investigators concluded, as did we, that glycogenesis, gluconeogenesis, and glycolysis were occurring simultaneously in the liver, and both reports are congruent with the postulate that intrahepatic glycolysis is an important source of substrates for the indirect pathway of glycogen synthesis.

In summary, this study provides the most detailed information yet available regarding the relationship between hepatic glycogen synthesis and carbon flux across the liver in vivo. During a continuous intraduodenal glucose infusion in conscious dogs, we were able to account for the gut disposition of 90\% of the glucose administered, either as glucose appearing in the portal vein or as products of gut glucose metabolism. In a net sense, $53 \%$ of the absorbed glucose was taken up by the liver, $3 \%$ remained within the glucose space, $24 \%$ was taken up by non-insulin-dependent tissues and $20 \%$ was available for uptake by muscle and adipose tissue. Thus, the liver was more than twice as important as muscle in disposal of the glucose load. The net hepatic uptake of all gluconeogenic precursors (gluconeogenic amino acids, lactate, and glycerol) was insuffcient to provide substrates for the $43 \%$ of glycogen synthesis which occurred via the indirect pathway, while the net hepatic glucose uptake was adequate to account for all net glycogen synthesis via both pathways. These data are consistent with the concept that, in a net sense, intrahepatic glycolysis is the source of most of the three-carbon substrates for glycogen synthesis by the indirect pathway. Interestingly, the mass of glycogen formed via the direct pathway remained within a narrow range, whereas that synthesized via the indirect pathway varied widely. Animals with the greatest percentage contribution by the indirect pathway also had the greatest total glycogen synthesis. The rate of synthesis via the indirect pathway appeared to serve as a set point which determined the total mass of glycogen synthesized.

\section{Acknowledgments}

We appreciate the excellent technical assistance of Mark Lufburrow.

This investigation was supported by National Institutes of Health grants DK-40936 and R01-AM-18243-14 and Diabetes Research and Training Center Grant SP-60-AM-20593-10. M. C. Moore received support from the Training in Nutrition Grant 5T32 DK-07083.

\section{References}

1. Katz, J., M. Kuwajima, D. W. Foster, and J. D. McGarry. 1986. The glucose paradox: new perspectives on hepatic carbohydrate metabolism. Trends Biochem. Sci. 11:136-140.

2. Kurland, K. J., and S. J. Pilkis. 1989. Indirect versus direct routes of hepatic glycogen synthesis. FASEB (Fed. Am. Soc. Exp. Biol.) J. 3:2277-2281.

3. Newgard, C. B., L. J. Hirsch, D. W. Foster, and J. D. McGarry. 1983 Studies on the mechanism by which exogenous glucose is converted into liver glycogen in the rat: a direct or an indirect pathway? J. Biol. Chem. 258:80468052.

4. Shulman, G. I., G. Cline, W. C. Schumann, V. Chandramouli, K. Kumaran, and B. R. Landau. 1990. Quantitative comparison of the pathways of hepatic glycogen repletion in fed and fasted humans. Am. J. Physiol. 259:E335E341.

5. Kalderon, B., A. Gopher, and A. Lapidot. 1986. Metabolic pathways leading to liver glycogen repletion in vivo, studied by GC-MS and NMR. FEBS (Fed. Eur. Biochem. Soc.) Lett. 204:29-32.

6. Shulman, G. I., D. L. Rothman, D. Smith, C. M. Johnson, J. B. Blair, R. G. Shulman, and R. A. DeFronzo. 1985. Mechanism of liver glycogen repletion in vivo by nuclear magnetic resonance spectroscopy. J. Clin. Invest. 76:1229-1236.

7. Bratusch-Marrain, P. R., W. K. Waldhausl, S. Gasic, A. Korn, and P. Nowotny. 1980. Oral glucose tolerance test: effect of different glucose loads on splanchnic carbohydrate and substrate metabolism in healthy man. Metab. Clin. Exp. 29:289-295.

8. Moore, M. C., J. Asher, A. Cherrington. 1990. Influence of hepatic nerves on the liver's response to a mixed meal. FASEB (Fed. Am. Soc. Exp. Biol.) J. 4:A519.

9. Hendrick, G. K., R. T. Frizzell, P. E. Williams, and A. D. Cherrington. 1990. Effect of hyperglucagonemia on hepatic glycogenolysis and gluconeogenesis after a prolonged fast. Am. J. Physiol. 258:E841-E849.

10. Shoemaker, W., W. Walker, T. Van Itallie, and F. Moore. 1948. A method for simultaneous catheterization of major hepatic vessels in a chronic canine preparation. Am. J. Physiol. 196:311-314.

11. Hartley, C. J., and J. S. Cole. 1974. An ultrasonic pulsed Doppler system for measuring blood flow in small vessels. J. Appl. Physiol. 37:626-629.

12. Goresky, C. A., C. G. Bach, and B. E. Nadeau. 1975. Red cell carriage of label: its limiting effect on the exchange of materials in the liver. Circ. Res. 36:328-351.

13. Lloyd, B., J. Burrin, P. Smythe, and K. G. M. M. Alberti. 1978. Enzymatic fluorometric continuous-flow assays for blood glucose, lactate, pyruvate, alanine, glycerol, and 3-hydroxybutyrate. Clin. Chem. 24:1724-1729.

14. Aguilar-Parada, E., A. M. Eisentraut, and R. H. Unger. 1969. Pancreatic glucagon secretion in normal and diabetic subjects. Am. J. Med. Sci. 257:415419.

15. Cherrington, A. D., J. L. Chiasson, J. E. Liljenquist, A. S. Jennings, U. Keller, and W. W. Lacy. 1976. The role of insulin and glucagon in the regulation of basal glucose production in the postabsorptive dog. J. Clin. Invest. 58:14071418.

16. Leevy, C. M., C. L. Mendenhall, W. Lesko, M. M. Howard. 1962. Estimation of hepatic blood flow with indocyanine green. J. Clin. Invest. 41:1169-1179.

17. Wide, L., and J. Porath. 1966. Radioimmunoassay of proteins with the use of Sephadex-coupled antibodies. Biochim. Biophys. Acta. 130:257-260.

18. Bidlingmeyer, B. A., S. A. Cohen, and T. L. Tarvin. 1984. Rapid analysis of amino acids using pre-column derivatization. J. Chromatogr. Biomed. Appl. 336:93-104.

19. Heinrikson, R. L., and S. C. Meredith. 1984. Amino acid analysis by reverse-phase high pressure liquid chromatography: precolumn derivatization with phenylisothiocyanate. Anal. Biochem. 136:65-74.

20. Keppler, D., and K. Decker. 1974. Glycogen: determination with amyloglucosidase. In Methods of Enzymatic Analysis. H. U. Bergmeyer, editor. Verlag Chemie Weinheim, Academic Press, Inc., New York. 1127-1131.

21. Abumrad, N. N., A. D. Cherrington, P. E. Williams, W. W. Lacy, and D. Rabin. 1982. Absorption and disposition of a glucose load in the conscious dog. Am. J. Physiol. 242:E398-E406.

22. Ferrannini, E., O. Bjorkman, G. A. Reichard, Jr., A. Pilo, M. Olsson, J. Wahren, and R. A. DeFronzo. 1985. The disposal of an oral glucose load in healthy subjects: a quantitative study. Diabetes 34:580-588.

23. Radziuk, J., T. J. McDonald, D. Rubenstein, and J. Dupre. 1978. Initial splanchnic extraction of ingested glucose in normal man. Metab. Clin. Exp. 27:657-669.

24. Cahill, G. F., Jr., and O. E. Owen. 1968. Some observations on carbohydrate metabolism in man. In Carbohydrate Metabolism and Its Disorders. F Dickens, P. J. Randle, and W. J. Whelan, editors. Academic Press, Inc., New York. 497-522.

25. Gottesman, I., L. Mandarino, and J. Gerich. 1984. Use of glucose uptake and glucose clearance for the evaluation of insulin action in vivo. Diabetes. 33:184-192.

26. Barrett, E., J. E. Ferrannini, R. Gusberg, S. Bevilacqua, and R. A. DeFronzo. 1985. Hepatic and extrahepatic splanchnic glucose metabolism in the postabsorptive and glucose fed dog. Metab. Clin. Exp. 34:410-420.

27. Bergman, R. N., J. R. Bier, and P. M. Hourigan. 1982. Intraportal glucose infusion matched to oral glucose absorption: lack of evidence for "gut factor" involvement in hepatic glucose storage. Diabetes. 31:27-35.

28. Adkins-Marshall, B. A., S. R. Myers, G. K. Hendrick, P. E. Williams, K. Triebwasser, B. Floyd, and A. D. Cherrington. 1990. Interaction between insulin and glucose-delivery route in regulation of net hepatic glucose uptake in conscious dogs. Diabetes. 39:87-95.

29. Nilsson, L. H., and E. Hultman. 1974. Liver and muscle glycogen in man after glucose and fructose infusion. Scand. J. Clin. Lab. Invest. 33:5-10.

30. Bishop, J. S., R. Steele, N. Altszuler, A. Dunn, C. Bjerknes, and R. C. DeBodo. 1965. Effects of insulin on liver glycogen synthesis and breakdown in the dog. Am. J. Physiol. 208:307-316.

31. Reaven, G. M., and J. M. Olefsky. 1977. Relationship between heterogeneity of insulin responses and insulin resistance in normal subjects and patients with chemical diabetes. Diabetes. 13:201-206.

32. Olefsky, J. M., G. M. Reaven, and P. Alto. 1974. Insulin and glucose response to identical oral glucose tolerance tests performed forty-eight hours apart. Diabetes. 23:449-453.

33. Pilkis, S. J., D. M. Regen, T. H. Claus, and A. D. Cherrington. 1985. Role of hepatic glycolysis and gluconeogenesis in glycogen synthesis. Bioessays. 2:273276. 
34. Cahill, G. F., Jr., A. B. Hastings, J. Ashmore, and S. Zottu. 1958. Studies on carbohydrate metabolism in rat liver slices. X. Factors in the regulation of pathways of glucose metabolism. J. Biol. Chem. 230:125-135.

35. Jacot, E., R. A. DeFronzo, E. Jequier, E. Maeder, and J.-P. Felber. 1982. The effect of hyperglycemia, hyperinsulinemia, and route of glucose administration on glucose oxidation and glucose storage. Metab. Clin. Exp. 31:922-930.

36. Elwyn, D. H., H. C. Parikh, and W. C. Shoemaker. 1968. Amino acid movements between gut, liver, and periphery in unanesthetized dogs. Am. J. Physiol. 215:1260-1275.

37. Elwyn, D. H., W. J. Launder, H. C. Parikh, and E. M. Wise, Jr. 1972. Roles of plasma and erythrocytes in interorgan transport of amino acids in dogs. Am. J. Physiol. 222:1333-1342.

38. Jungermann, K. 1988. Metabolic zonation of liver parenchyma. Semin. Liver Dis. 8:329-341.

39. Shulman, G. I., D. L. Rothman, T. Jue, P. Stein, R. A. DeFronzo, and R. G. Shulman. 1990. Quantitation of muscle glycogen synthesis in normal subjects and subjects with non-insulin-dependent diabetes by ${ }^{13} \mathrm{C}$ nuclear magnetic resonance spectroscopy. N. Engl. J. Med. 322:223-228.
40. Johnson, J. L., and G. J. Bagby. 1988. Gluconeogenic pathway in liver and muscle glycogen synthesis after exercise. J. Appl. Physiol. 64:1591-1599.

41. Marin, P., M. Rebuffe-Scrive, U. Smith, and P. Bjorntorp. 1987. Glucose uptake in human adipose tissue. Metab. Clin. Exp. 36:1154-1160.

42. Coppack, S. W., K. N. Frayn, P. L. Whyte, and S. M. Humphreys. 1989. Carbohydrate metabolism in human adipose tissue in vivo. Biochem. Soc. Trans. 17:145-146.

43. Frayn, K. N., S. W. Coppack, S. M. Humphreys, and P. L. Whyte. 1989. Metabolic characteristics of human adipose tissue in vivo. Clin. Sci. (Lond.). 76:509-516.

44. Jackson, R. A., J. B. Hamling, B. M. Sim, M. I. Hawa, P. M. Blix, and J. D. N. Nabarro. 1987. Peripheral lactate and oxygen metabolism in man: the influence of oral glucose loading. Metab. Clin. Exp. 36:144-150.

45. Mitrakou, A., J. Milde, J. Michenfelder, and J. Gerich. 1989. Rates of lactate appearance and disappearance and brain lactate balance after oral glucose in the dog. Horm. Metab. Res. 21:236-239.

46. Mitrakou, A, R. Jones, Y. Okuda, J. Pena, N. Nurihan, J. B. Field, and J. E. Gerich. 1991. Pathway and carbon sources for hepatic glycogen repletion in dogs. Am. J. Physiol. 260:E194-E202. 